Printed in Great Britain

\title{
THE LIFE HISTORIES AND POPULATION DYNAMICS OF MONOGENEAN GILL PARASITES OF TRACHURUS TRACHURUS (L.)
}

\author{
By J. Llewellyn, D.Sc. \\ Department of Zoology and Comparative Physiology, \\ The University, Birmingham I5
}

(Text-figs. I and 2)

During the course of various studies, spread over several years, of monogenean parasites of the gills of fishes at Plymouth, only adult specimens of Gastrocotyle trachuri van Beneden \& Hesse and Pseudaxine trachuri Parona \& Perugia have been found on Trachurus trachurus (L.) (the Scad, or Horse Mackerel) in July, August and September, but larvae, juveniles, and adults have been found all to occur together in May (Llewellyn, 1959). It was decided therefore to attempt to find out the pattern of changes in the structure of the populations of gill parasites on scad throughout the year at Plymouth.

As a result of experience gained in the earlier study of the larval development of the parasites (Llewellyn, 1959, Table I), it was decided to examine samples, each so far as possible of six fishes, of two kinds: (a) fishes in their first year of life ('o Group') at regular monthly intervals ( 57 fishes examined); and $(b)$ older fishes in certain other selected months, as indicated on p. 595 (I26 fishes examined). The host fishes were caught between the Breakwater and Eddystone as near as practicable to the middle of each month. Some of them were examined fresh at Plymouth, but most of them were deep-frozen $\left(-10^{\circ} \mathrm{C}\right)$ for about a week before being sent in an insulated container to Birmingham, where they were examined either immediately or after further storage for 2 or 3 days at $-10^{\circ} \mathrm{C}$. Comparative tests carried out at Plymouth indicated that the accumulation of gill mucus during cold storage made no appreciable difference to the total number of parasites collected from fresh and deep-frozen hosts.

The gills were removed from the fishes and each arch was transferred separately to a dish of sea water to which had been added a few drops of propylene-phenoxetol as a bactericide. The gill filaments were then examined with a stereomicroscope in combined transmitted and incident light at a magnification of $\times$ Io, and the parasites were freed from the gills with a needle and then pipetted on to a slide for measuring to the nearest $0.1 \mathrm{~mm}$. In order to eliminate variations due to differences in expansion under coverglass pressure, the parasites were left uncovered. Records were kept of the length of each host fish in order to estimate its age from histograms constructed from 
data from standard-haul trawl sampling by Captain J. Creese, Mr A. D. Mattacola, and the late Dr G. A. Steven (see below), and of the identity, numbers, and lengths of its parasites.

As the work went on, it became increasingly obvious that some knowledge of the general biology of the hosts was essential for any understanding of the variations in the parasite populations. T. trachurus is of no economic importance in Britain, but is fished commercially in France, Spain, Portugal, Italy, the Black Sea countries, South Africa, and elsewhere. Thus some biometric studies of scad have been made in Spain by Planas \& Vives (I953), in South Africa by Davies (1957), and in Italy by Matta (1958), but the only attempt at a comprehensive account of the general biology of Trachurus is that from La Rochelle, France, by Letaconnoux (I95I). For information about Trachurus at Plymouth, I am very grateful to Dr F. S. Russell for permission to make use of some previously unpublished records of Otter-trawl sampling carried out by Captain J. Creese, Captain C. A. Hoodless, Mr A. D. Mattacola, and the late Dr G. A. Steven in 1949-52 and in 1953-57. In I949-52 there were repeated as nearly as practicable with R.V. 'Sabella' the trawling investigations which had been carried out previously by E. Ford and R. S. Clark with

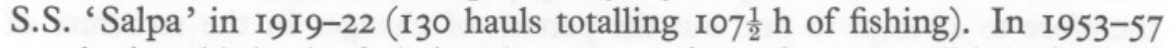
standard weekly hauls of $\mathrm{I} h$ duration were made as often as possible in daylight hours (between 10.00 and $14.00 \mathrm{~h}$ ) at a depth of approximately $50 \mathrm{~m}$ at a position about mid-way between the Breakwater and Eddystone (Plymouth Laboratory Station L4), the trawl having its cod-end covered with a net of small (I2 mm) mesh. A total of 138 standard hauls was made, yielding, among the catch, $8235 \mathrm{scad}$. The fishes used for the parasitological study were obtained from the same area in 1959-60. In view of the relative paucity and scattered nature of the published information about the hosts, a summary of what is known about the occurrence, life cycle, and migrations of $T$. trachurus has been compiled from the Plymouth records referred to above, and from the literature, for inclusion in the present paper.

\section{THE OCCURRENCE AND LIFE HISTORY OF TRACHURUS TRACHURUS}

Among the noteworthy changes in the catch following the 30-year interval between the I9I9-22 trawl-sampling by 'Salpa' and the 1949-52 sampling by 'Sabella' referred to previously was the great increase in the occurrence of what had been regarded as a southern warm-water fish, $T$. trachurus. This species appeared in only two of the 130 standard hauls made in 1919-22 (total number of scad caught $=4$ ), but in I6 of the same number of hauls in 1949-52 (total number of scad caught $=300$ ).

Spawning in Trachurus takes place in June, July and August (Clark, I922), and according to various authorities the eggs may be between $0.8 \mathrm{I}$ and 
$\mathrm{I} .09 \mathrm{~mm}$ in diameter and are pelagic. The embryos hatch after 3-4 days at temperatures of between $15^{\circ}$ and $19^{\circ} \mathrm{C}$ (Letaconnoux, 195I) when they are $2.5 \mathrm{~mm}$ long (Kennedy, I954), and the larva is pelagic. Russell (1930, 1935) found post-larvae of $4-15 \mathrm{~mm}$ long in only the months of July to October inclusive (maximum frequency in August) in regular ring-trawl samples of waters off-shore from Plymouth (Laboratory Stations L 4 and L 6, and 2 miles east of Eddystone). These post-larvae tended to be nearer the surface than in the deeper water. Corbin (1948, I949) confirmed that the pelagic post-larval scad are found only in the months of July to October inclusive.

Adolescents of $3.5-6.5 \mathrm{~cm}$ were found by Clarke (1922) in off-shore waters between Rame Head, Eddystone, and the 40-fathom line, as well as in very shallow water close inshore in Cawsand Bay and Whitsand Bay in July, August and September, with a maximum frequency in August. Mr G. R. Forster (personal communication), in the course of diving investigations in the Plymouth area during the past ro years, has observed scad of about $5-8 \mathrm{~cm}$ long in the Sound in only the month of September. But according to Couch (I863), late-hatched fry may be only $2.5 \mathrm{~cm}$ or less by the end of the year.

In waters off-shore from Plymouth (Laboratory Station $\mathrm{L}_{4}, 50 \mathrm{~m}$ deep) the young summer-hatched scad (o Group) first appear in the covered codend ( $12 \mathrm{~mm} \mathrm{mesh}$ ) of the trawl in late September and early October, when they are about $10.5(6.5-12.0) \mathrm{cm}$ long (see Figs. I B and IC). In these same waters there is a continued and gradual build-up in the population of o-Group scad throughout the autumn, but after January the numbers begin to fall (Fig. I B); presumably by this time mortalities are in excess of the numbers of new recruits. This decrease in the population of o-Group scad continues gradually until July, when there is a sudden and complete disappearance of these young fishes from the sea-bottom in the sampling area.

Little information is available about the whereabouts of the scad in August and September. Meek (I9I6) stated that as the summer advances the scad approach the shore, swimming high, and are frequently taken by mackerel nets as well as by hooks and lines. Meek offered no records of actual observations to support his statement, but Hartley (1940), in the course of regular tuck-net sampling throughout the year, caught scad in the Tamar Estuary in the months of July and August only. Dr G. T. Boalch (personal communication) has reported that $T$. trachurus sometimes appears in quantity in seinenettings, but only in the months of July, August and September, at Beer, Devon, where the fishes are known locally as 'Scousers', 'Scouse-pigs', or 'French mackerel'.

It seems probable that the disappearance of $T$. trachurus from the sea bottom and its appearance simultaneously in in-shore surface waters in summer months is associated with its feeding habits. According to Letaconnoux (I95I), various investigators have found that in summer the gut contains mainly pelagic organisms, especially the following: copepods; 
prawns, shrimps (Palaemon, Crangon); the eggs and larvae of fishes; and the young of anchovies, sprats, sardines, herring, and whiting; and, less frequently, diatoms and peridineans. In winter it contains benthic and deep pelagic crustaceans, and bottom-living fishes, molluscs, and echinoderms. It is highly probable, then, that the scad leave the sea bottom in summer in search of a different kind of food, and this would account for why they are not caught in the trawl at Plymouth in August and September.

When they leave the sea bottom in July the o-Group scad at Plymouth are $\mathrm{I} 2.8(10.5-14.5) \mathrm{cm}$ long, and when they return there in October of the same year they are $17.3(14 \cdot 0-18 \cdot 5) \mathrm{cm}$ long (see Fig. IC). According to Letaconnoux (I95I) these young scad become sexually mature in the following summer at a length of about $19-20 \mathrm{~cm}$ (in the Plymouth samples the scad at the end of their second year had grown to a length of $18(\mathrm{I} 7-2 \mathrm{I}) \mathrm{cm})$, and those scad that have spawned leave coastal waters, not returning until the following April, when together with other returning older scad, they join a 'pre-spawning assembly'. This well-marked and sudden increase in the total population of scad in Plymouth waters is well known, and was said by Couch (I863) to be associated with an up-Channel migration of the species. I have been unable to find any evidence to support the view that such an up-Channel migration actually takes place, but Letaconnoux (I95I) has given some evidence which suggests that there is an annual migration of scad from the Bay of Biscay to the Celtic Sea and back, the migrants passing the Plymouth area in March and April on their northward journey. The observed increase in the numbers of old scad at Plymouth in April (see Fig. IA) would be consistent with these scad belonging to this southern stock, but there is no evidence of an increase in the numbers at Plymouth when the migrants are thought to pass this area again in about August on their return journey. At the end of their third year the scad have reached a length of about $24 \mathrm{~cm}$, at the end of their fourth $29 \mathrm{~cm}$, fifth $33 \mathrm{~cm}$, sixth $35 \mathrm{~cm}$, and seventh $37 \mathrm{~cm}$. They generally live to an age of 6 years, though rarely to 7,8 , or even 9 years (Letaconnoux, 1951).

From the parasitological aspect, two features of the life cycle of $T$. trachurus are of particular importance: first, the almost complete disappearance of scad (of all ages) from the sea bottom in summer; and secondly, the confinement

\section{Legend to Fig. I}

Fig. IA-C. The relative mean monthly frequency of T. trachurus at Plymouth in I953-57, based on standard haul trawl sampling by Captain J. Creese, Mr A. D. Mattacola and the late Dr G. A. Steven (see text, p. 588). A, Fishes of all ages; B, O-Group fishes only; c, numbers of o-Group fishes measured at $0.5 \mathrm{~cm}$ length intervals and expressed as a percentage of the total sample for the month. I D, The numbers of G. trachuri, measured at $0.5 \mathrm{~mm}$ intervals of length, on standard monthly samples of o-Group to I + group T. trachurus from October I 959 to October 1960. (The stippled areas represent small non-standard samples of T. trachurus caught outside the r $959-60$ sampling period.) 

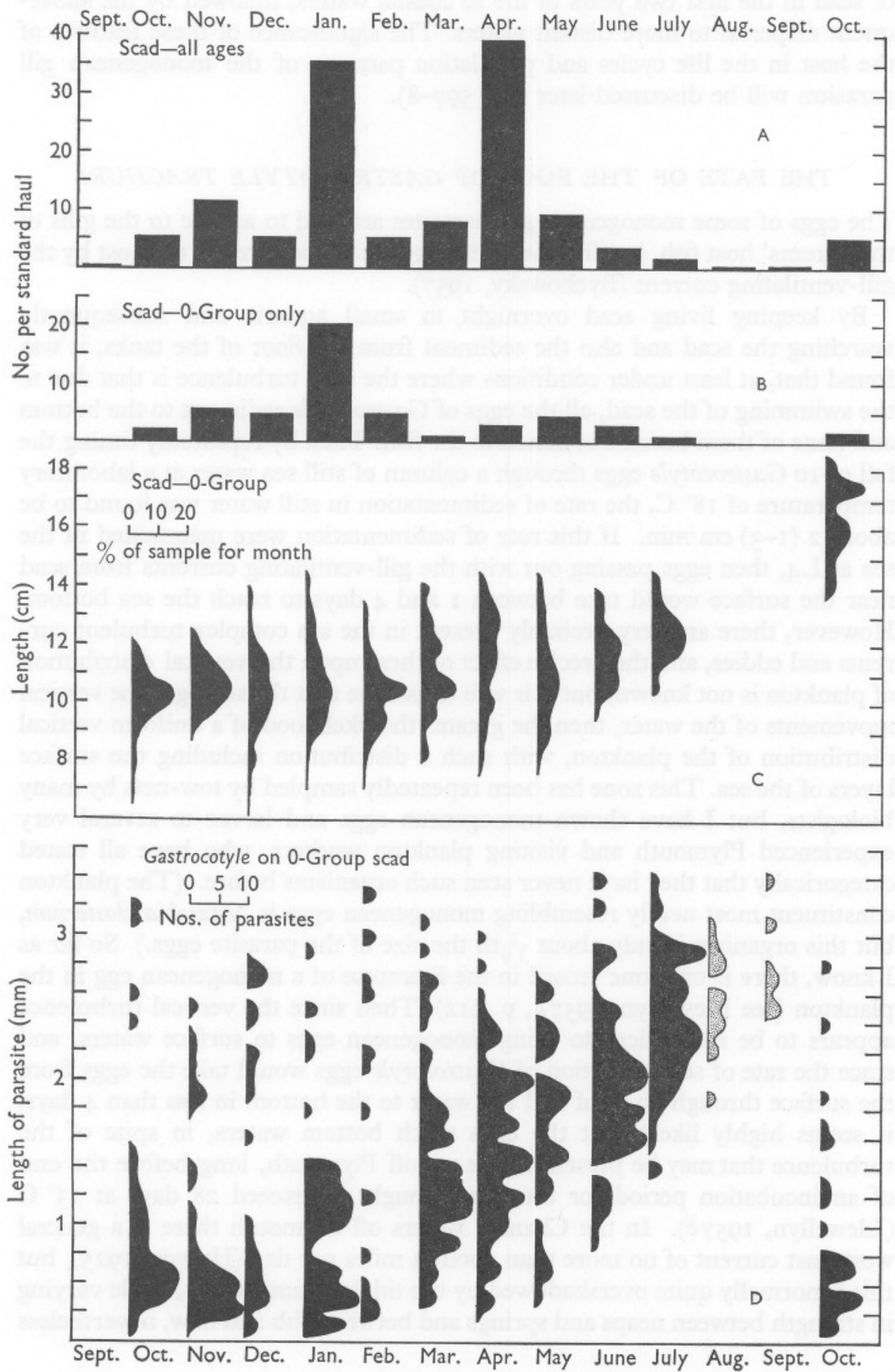

Fig. I. For legend see opposite page. 
of scad in the first two years of life to coastal waters, followed by the subsequent dispersal to more distant waters. The significance of these features of the host in the life cycles and population patterns of the monogenean gill parasites will be discussed later (pp. 597-8).

\section{THE FATE OF THE EGGS OF GASTROCOTYLE TRACHURI}

The eggs of some monogenean gill parasites are said to adhere to the gills of the parents' host fish, but in others the eggs are carried free of the host by the gill-ventilating current (Bychowsky, 1957).

By keeping living scad overnight in small aquaria and subsequently searching the scad and also the sediment from the floor of the tanks, it was found that, at least under conditions where the only turbulence is that due to the swimming of the scad, all the eggs of Gastrocotyle sediment to the bottom and none of them become attached to the fish. Then by repeatedly timing the fall of Io Gastrocotyle eggs through a column of still sea water at a laboratory temperature of $18^{\circ} \mathrm{C}$, the rate of sedimentation in still water was found to be about $2(\mathrm{I}-3) \mathrm{cm} / \mathrm{min}$. If this rate of sedimentation were maintained in the sea at $\mathrm{L} 4$, then eggs passing out with the gill-ventilating currents from scad near the surface would take between I and 4 days to reach the sea bottom. However, there are very probably present in the sea complex turbulent currents and eddies, and the precise effect of these upon the vertical distribution of plankton is not known, but it is safe to assume that the stronger the vertical movements of the water, then the greater the likelihood of a uniform vertical distribution of the plankton, with such a distribution including the surface layers of the sea. This zone has been repeatedly sampled by tow-nets by many biologists, but I have shown monogenean eggs and larvae to several very experienced Plymouth and visiting plankton workers, who have all stated categorically that they have never seen such organisms before. (The plankton constituent most nearly resembling monogenean eggs is Nitzschia closterium, but this organism is only about $\frac{1}{10}$ th the size of the parasite eggs.) So far as I know, there is only one record in the literature of a monogenean egg in the plankton (see Llewellyn, I957a, p. 212). Then since the vertical turbulence appears to be insufficient to bring monogenean eggs to surface waters, and since the rate of sedimentation of Gastrocotyle eggs would take the eggs from the surface through $50 \mathrm{~m}$ of still sea water to the bottom in less than 4 days, it seems highly likely that the eggs reach bottom waters, in spite of the turbulence that may be present in the sea off Plymouth, long before the end of an incubation period for the eggs thought to exceed 28 days at $13^{\circ} \mathrm{C}$ $($ Llewellyn, $1957 b$ ). In the Channel waters off Plymouth there is a general west-east current of no more than about 3 miles per day (Harvey, I925), but this is normally quite overshadowed by the tidal streams which, while varying in strength between neaps and springs and between ebb and flow, nevertheless 
preserve a mean of about $0.4(0.1-0.9)$ knots, i.e. about I3 $(3-27) \mathrm{m} / \mathrm{min}$; these tidal streams veer through $360^{\circ}$ during each day (Hydrographic Department of the Admiralty, I942). The general conclusion, then, is that Gastrocotyle oncomiracidia would hatch in bottom waters within a few miles of where they were laid. The behaviour of these oncomiracidia has not been studied (and the larva has a pair of eyes, see Llewellyn, $1957 b$ ), but the life of free-living specimens in culture dishes at $18^{\circ} \mathrm{C}$ does not exceed one day, and so the inference is that the population of active oncomiracidia of Gastrocotyle would be largely confined to bottom waters. Nothing is known of the manner of invasion of scad by Gastrocotyle larvae.

\section{THE INCIDENCE OF GASTROCOTYLE TRACHURI ON O-GROUP TRACHURUS TRACHURUS}

All specimens of a sample of ten pelagic larvae of T. trachurus, all less than $2 \mathrm{~cm}$ long, and all caught at mid-water levels in the young-fish trawl in August 1959, were found to be free from gill parasites. This gives some support to the suggestion made above that the free-living larvae of Gastrocotyle inhabit principally bottom waters, though it will be pointed out later (p. 598) that oncomiracidia may not in any case occur in August.

o-Group scad are not normally caught in the covered cod-end of the trawl at Plymouth in September, and none appeared in the standard hauls in 195357, but in September 1959 three specimens occurred. None of them was infected with any gill parasites.

In October I959 five o-Group scad were obtained in the standard parasitological samples, and all five were found to be parasitized with Gastrocotyle, the mean rate of infestation being 8.2 parasites per fish, and the maximum degree of infestation being 15 parasites per fish. Most of the parasites ( 36 out of a total of $4 \mathrm{I}$ ) were under $\mathrm{I} \cdot 9 \mathrm{~mm}$ long and immature, but a few large egg-laying specimens were present also. Therefore unless adult specimens are able to transfer from one fish to another (and there is some evidence that they cannot do this), or unless some oncomiracidia do in fact invade young Trachurus before the fish descends to the sea bottom, it appears that $G$. trachuri is capable of becoming sexually mature and fully grown within a period of no longer than about four weeks.

Through the autumn and winter there was little change either in the mean size of the population (about 8 per fish) from month to month or in the mean length of the parasites (about $0.9 \mathrm{~mm}$ ). It appears then that the parasites were not in a very active growth phase. Moreover, it appeared that no great losses from the population were taking place, for if there were, the losses would presumably be spread over juveniles of all lengths, and with any compensations coming only from newly invading oncomiracidia (about $0.2 \mathrm{~mm}$ long), the net result would have been a gradual decrease in the mean 
length of individuals of the population. Since, however, this did not happen, the inference is that through the winter there is a static population of mainly juvenile parasites.

In the spring, and approximately coincident with a corresponding activity in the life of the host, growth of the parasites recommences and at the same time the total number of parasites begins to increase, perhaps due to some of the over-wintering juveniles having become sexually mature and so adding to the reproductive capacity of the population.

The same trends, namely, relatively rapid growth and increased reproductive activity, continue through the spring, but in May the invasion by recently hatched oncomiracidia ceases, the level of the total population is stabilized, and the whole population grows up. While some very young juveniles (less than $0.5 \mathrm{~mm}$ long) had been present continuously from October to May, in succeeding months the smallest parasites found were progressively longer (see Fig. ID): in June they were $0.9 \mathrm{~mm}$, and in July $\mathrm{I} .4 \mathrm{~mm}$. o-Group scad are not normally caught in the trawl at Plymouth in August and September, but three specimens were caught on 3 August I96I, and two on II September 1959; the lengths of all five specimens were consistent with them having been hatched in the summer of the year previous to that of their capture. The smallest parasites collected from these fishes were $I .9 \mathrm{~mm}$ long from the August hosts, and $2.5 \mathrm{~mm}$ long from the September hosts.

When the young scad begin their second autumn in October, they carry a predominantly juvenile population of Gastrocotyle ( 30 out of 33 specimens shorter than $\mathrm{I} .9 \mathrm{~mm}$, and the whole population having a mean length of $0.9 \mathrm{~mm}$, see Fig. ID), and so it is inferred that most of the adults of the previous summer have died, since nearly all o-Group scad towards the end of their first year of life carry each about ten fully grown parasites and no juveniles. It is concluded therefore that the normal life span of G. trachuri is no longer than I year, i.e. from October to the following September, and possibly less.

\section{THE INCIDENCE OF GASTROCOTYLE TRACHURI ON TRACHURUS TRACHURUS OF VARIOUS AGES}

It was shown earlier that young juveniles of Gastrocotyle occur in May on hosts of all ages"up to and including 3 years (Llewellyn, 1959). In the present study juveniles have been found on hosts of the age-groups mentioned in October, February, and April, but to be absent in July, August and most of September. It seems highly probable then that the pattern of occurrence through the year of juvenile parasites on older hosts $(\mathrm{I}+$ to $3+)$ follows that shown for o-Group hosts: juvenile G. trachuri occur commonly from October to May, become scarce in June, and are no longer found in July, August, and September. It is thus confirmed that $T$. trachurus shows no age-immunity to G. trachuri. 
The relative degrees of infestation with $G$. trachuri of six different agegroups of $T$. trachurus are shown in Figs. 2A and 2B, which were constructed from data included in the o-Group records given above (pp. 593-4 and Fig. I D), and from observations on a total of 430 parasites collected from 126 hosts belonging to $\mathrm{I}+, 2+$, and $3+$ scad caught in October, February, April, May,



Fig. 2. The occurrence of G. trachuri on T. trachurus of various ages, based on samples of fishes (o to $3+$ groups) caught by MBA vessels in October, February, April, May, July, August and September, together with a small sample ( $4+$ and $5+$ age-groups) caught by M.T. 'Pentillie' in April, 1962. A, Percentage of Trachurus infected; B, degree of infestation in parasites per fish.

July, August and September, together with a more limited sample of nine specimens of $4+$ scad and three specimens of $5+$ scad caught in April 1962 by the M.T. 'Pentillie' at a position Io miles south of Eddystone. (No fishes older than 4 years had turned up in the M.B.A. trawler samples of fishes searched for parasites, the longest fish examined being $30.2 \mathrm{~cm}$. In the 1953-57 standard hauls only three fishes of over $30 \mathrm{~cm}$ were reported, and these had lengths of 32,39 and $40 \mathrm{~cm}$ respectively.)

From Figs. $2 \mathrm{~A}$ and $2 \mathrm{~B}$ it may be seen that in their first two years nearly all scad (98-100\%) are infested with Gastrocotyle, with the mean parasite burden being about 12 per fish, but that in their third and fourth years the number of parasitized fishes in the population falls to about a half, with the number of parasites per fish falling to about two. In the small sample of hosts in their fifth year, one out of nine specimens (II \%) was infected with two fully grown specimens of Gastrocotyle (2.5 and $2.7 \mathrm{~mm}$ long respectively) and one fully grown specimen of Pseudaxine (2.7 $\mathrm{mm}$ long); all three hosts in their sixth year were without parasites. It is relevant to note that during a collecting 
cruise in August 1938 in deep water $(300 \mathrm{~m})$ off N.W. Ireland at a position $54^{\circ} \mathrm{O}^{\prime} \mathrm{N}$., $\mathrm{II}^{\circ} \mathrm{IO}^{\prime} \mathrm{E}$. (see Rees \& Llewellyn, I94I) I examined the gills of thirty 'large' specimens of $T$. trachurus; no monogeneans were found, but several of the fishes were recorded as bearing on their gills spherical cysts, each of less than I mm in diameter, and so it is likely that if any specimens of Gastrocotyle or Pseudaxine had been present they would have been seen. Williams (1960) has also examined $T$. trachurus from non-coastal waters but has not recorded any monogeneans on their gills.

\section{COMPARISON OF THE LIFE HISTORIES AND POPULATION DYNAMICS \\ OF PSEUDAXINE TRACHURI AND GASTROCOTYLE TRACHURI}

It has been stated (Llewellyn, 1956) that $P$. trachuri attaches itself near the distal regions of the primary gill lamellae of $T$. trachurus. During the present study a more detailed investigation of the region of attachment was made, and a comparison made with the site of attachment of $G$. trachuri. In a sample of 77 parasites, 69 specimens of Gastrocotyle were found all to be attached to the proximal three-quarters of the primary lamellae, and eight Pseudaxine all to be attached to the distal quarter.

The relative frequencies of occurrence of Pseudaxine and Gastrocotyle on Trachurus found in the present investigations are given in Table $\mathrm{I}$.

TABLE 1. OCCURRENCE OF GASTROCOTYLE TRACHURI AND PSEUDAXINE TRACHURI ON TRACHURUS TRACHURUS

\begin{tabular}{|c|c|c|c|c|c|}
\hline \multirow{2}{*}{$\begin{array}{l}\text { Age of } \\
\text { Trachurus }\end{array}$} & \multicolumn{2}{|c|}{$\%$ infestation } & \multicolumn{2}{|c|}{ Parasites per fish } & \multirow[b]{2}{*}{ Gastrocotyle:Pseudaxine } \\
\hline & Gastrocotyle & Pseudaxine & Gastrocotyle & Pseudaxine & \\
\hline o Group & 98 & 84 & $10 \cdot 8$ & $2 \cdot 9$ & $3 \cdot 7: 1$ \\
\hline I + Group & 100 & 69 & 13.3 & $2 \cdot 3$ & $5 \cdot 8: 1$ \\
\hline $2+$ Group & 64 & 59 & $2 \cdot 6$ & $I \cdot I$ & $2 \cdot 4: I$ \\
\hline $3+$ Group & 54 & 22 & $I \cdot 7$ & 0.3 & $5 \cdot 7: 1$ \\
\hline
\end{tabular}

The mean length of individuals of the population of Pseudaxine on o-Group scad was found to remain constant at about $\mathrm{I} \cdot 2 \mathrm{~mm}$ from October to March, and then to increase fairly uniformly to reach $2.4 \mathrm{~mm}$ by July. Juveniles were not found in summer months, and adults became scarce and a new invasion of oncomiracidia appeared in early October.

From the above observations it may be concluded that the life cycle and pattern of changes in the population structure through the year of Pseudaxine on Trachurus are very similar to those of Gastrocotyle. Apart from the morphological differences between these parasites, the chief differences are in microhabitat, Pseudaxine attaching itself to the distal quarter of the primary lamellae and Gastrocotyle to the proximal three-quarters, and in the relative frequencies of occurrence, Gastrocotyle being much more common than Pseudaxine. It is possible that these differences may be related to each other, but the problem remains to be investigated. 


\section{DISCUSSION}

On the evidence of the foregoing observations, it would appear that the parasitism of Trachurus trachurus by Gastrocotyle trachuri and Pseudaxine takes the following pattern. Nearly all young post-larval scad become infected with oncomiracidia as soon as the young fishes descend to the sea bottom, beginning in very late September or early October. This is the time at which a high density of free-swimming oncomiracidia may be expected to occur: from Text-fig. ID (p. 59I) it may be inferred that, at least on o-Group scad, the population of sexually mature parasites is at its greatest in late summer; and if a laboratory-determined incubation period for Gastrocotyle in excess of 28 days at $13^{\circ} \mathrm{C}$ (Llewellyn, $1957 b$ ) approximates to what happens under natural conditions on the sea bed (sea-bottom temperature at Plymouth Laboratory Station $\mathrm{L}_{4}$ in August is $\mathrm{I}_{3}^{\circ} \mathrm{C}$ approximately, teste F. A. J. Armstrong, private communication), then a high density of newly hatched oncomiracidia is likely to occur in about late September.

While it is possible that some of the newly invaded oncomiracidia may mature relatively rapidly (less than 4 weeks, see p. 593), most of them grow more slowly, and a more normal development period probably extends over 3 or 4 months; as stated above (p. 594 and Fig. I D), very small juveniles of Gastrocotyle (less than $0.5 \mathrm{~mm}$ long) in May have all achieved sexual maturity ( $1.9 \mathrm{~mm}$ long) by August, and are fully grown (about $2.5-3.0 \mathrm{~mm}$ long) by September. The normal life span is less than one year, and during September most of the parasites die and are lost from the host.

When the I-year-old scad, after their summer of surface-feeding, descend again to the sea bottom in October, they pick up a new invasion of oncomiracidia, and for a second time in their lives they become parasitized by a population of mainly juvenile parasites. These juveniles come to maturity during the host's second year, and most of them are lost by the following September.

The scad leave the coastal waters after their first spawning towards the end of the second year of life, and this dispersal presumably leads to a decrease in the density of the population of scad in the more distant waters, and a still greater decrease in the chances of invasion by the correspondingly more sparsely distributed oncomiracidia if, indeed, the parasite continues to lay eggs when its host is away from coastal waters. Thus when the hosts return to coastal waters for the pre-spawning assembly in about April of their third (and succeeding) years, the incidence of Gastrocotyle and Pseudaxine on the gills has fallen very considerably.

G. trachuri and P.trachuri are thus essentially parasites of young T. trachurus, with the limiting factor being the habit of the host of migrating from coastal waters after spawning rather than an acquired age-immunity. Moreover, the reproductive activities of the parasites are closely linked with the seasonal 
change in the feeding habits of the young scad, the parasites becoming reproductively inactive in anticipation of the departure of the young scad from the sea bottom in July in order to become plankton feeders, and becoming active again in August in anticipation of the descent to the sea bottom in October of the young scad hatched in the previous summer. Nothing is known yet about the mechanics of the regulation of the reproductive activity of Gastrocotyle; it is possible that egg-production is suspended, or that a state of diapause may occur.

G. trachuri and P. trachuri are clearly distinguishable from each other on morphological grounds, and, indeed, have always been recognized by systematists as belonging to separate genera. However, while the relationship is unlikely to be so distant as this, there can be little doubt that there are two distinct species, and these either must have diverged from a common ancestor already adapted to the seasonal migratory and feeding habits of T. trachurus, or must have converged, after the initial divergence, in adapting their life cycles to that of the host. The former alternative seems much the more likely, and is, perhaps, an indicator of an antiquity of the feeding and migrating habits of T. trachurus.

As stated earlier (p. 588) there is some evidence that T. trachurus has come northwards in considerable numbers into Plymouth waters in only the last 30 years, but whether it brought with it an abundant monogenean parasite population (which would thus have been obliged to become adapted to Plymouth conditions), or whether the new fish hosts were colonized by the local parasite stock is, of course, not known. T. trachurus has been recorded from many geographical areas, e.g. South Africa, Japan and New Zealand (see Letaconnoux, 195I), and it will be interesting to discover whether its gill parasites, if such be present in these areas, exhibit the same close adaptation to their hosts as do their Plymouth counterparts.

Something appears to be known of the population dynamics of monogenean parasites on the gills of marine fishes in only four other parasite/host associations, namely Protancyrocephalus strelkowi on Limanda aspera at Shikotan Island in the Far East, Mazocraes alosae on Alosa spp. in the Caspian Sea, Kuhnia (= Octostoma) scombri and K. minor on Pneumatophorus japonicus in the Sea of Japan, and Microcotyle gotoi on Hexagrammos spp. at Shikotan Island and Southern Sakhalin, all described by Bychowsky (1957). In all of these Bychowsky has shown a relationship between the life cycles of the parasites and the migratory habits of the hosts, but there does not appear to be present in any of these associations the superimposed factor of an adaptation to a seasonal change in the feeding habits of the host.

I am very grateful to the Director and Staff of the Marine Biological Association Laboratory, so many of whom have helped in many ways during this investigation. 


\section{SUMMARY}

Gastrocotyle trachuri and Pseudaxine trachuri infect young Trachurus trachurus at Plymouth as soon as the 3-or 4-month-old adolescent fishes descend to the sea bottom in October. The parasites normally mature in 3 or 4 months, but, exceptionally, in about I month, and the life-span is normally no longer than I year. Trachurus specimens at the beginning of their second year pick up a largely new infection of parasites.

$G$. trachuri and $P$. trachuri are much less frequent on 2- and 3-year-old specimens of Trachurus and probably occur only very rarely on still older fishes, the limiting factor being not an age-immunity but a post-spawning migration of the host from the concentration of free-living infective stages of the parasites in coastal waters.

The parasites have adapted themselves to a seasonal change in the feeding habits of Trachurus by ceasing to produce larvae in anticipation of the summer disappearance of scad from the sea bottom in pursuit of pelagic food-organisms.

\section{REFERENCES}

Bychowsky, B. E., I957. Monogenetic Trematodes, their Classification and Phylogeny. 509 pp. Moscow: Leningrad, Academy of Sciences, U.S.S.R.

ClARK, R. S., I922. The pelagic young and early bottom stages of teleosteans. F. mar. biol. Ass. U.K., Vol. 12, pp. 159-240.

Corbin, P. G., I948. On the seasonal abundance of young fish. IX. The year 1947. F. mar. biol. Ass. U.K., Vol. 27, pp. 718-22.

CorbIN, P. G., I949. On the seasonal abundance of young fish. X. The year 1948. F. mar. biol. Ass. U.K., Vol. 28, pp. 707-I2.

Couch, J., I863. A History of the Fishes of the British Islands, Vol. 2, 265 pp. London: Groombridge and Sons.

Davies, D. H., I957. The South African Pilchard (Sardinops ocellata) and Maasbanker (Trachurus trachurus). Young fish survey, 1955-56. Invest. Rep. Fish. S. Afr., Pretoria, No. 29, 36 pp. (Reprint from Commerce and Industry, Oct. I957.)

Hartley, P. H. T., 1940. The Saltash tuck-net fishery and the ecology of some estuarine fishes. F. mar. biol. Ass. U.K., Vol. 24, pp. I-68.

Harvey, H. W., I925. Hydrography of the English Channel. Rapp. Cons. Explor. Mer, Vol. 37, pp. 59-9r.

Hydrographic Department of the Admiralty, 1942. Pocket Tidal Stream Atlas: English Channel. February 1942.

Kennedy, M., 1954. The Sea Angler's Fishes, 524 pp. London: Hutchinson.

Letaconnoux, R., I95I. Contribution à l'études des espèces du genre Trachurus et spécialement du Trachurus trachurus (Linné, 1758). Mém. Off. sci. tech. Pêch. marit., no. 15, 67 pp.

Llewellyn, J., I956. The host-specificity, micro-ecology, adhesive attitudes, and comparative morphology of some trematode gill parasites. F. mar. biol. Ass. U.K., Vol. 35, pp. Ir $3-27$.

- 1957a. Host specificity in monogenetic trematodes. In First Symposium on Host Specificity among Parasites of Vertebrates, pp. I9I-212. Neuchâtel. 
LlewellyN, J., 1957b. The larvae of some monogenetic trematode parasites of Plymouth fishes. F. mar. biol. Ass. U.K., Vol. 36, pp. 243-59.

1959. The larval development of two species of gastrocotylid trematode parasites from the gills of Trachurus trachurus. F. mar. biol. Ass. U.K., Vol. 38, pp. $46 \mathrm{I}-7$.

Matta, F., 1958. La pesca a strascico nell' Arcipelago Toscano. Boll. Pesca Piscic. Idrobiol., Vol. 13 (N.S.), Fasc. I-2, pp. 23-37I.

MeEK, A., I9I6. The Migrations of Fish. 427 pp. London: Arnold.

Planas, A. \& Vives, F., I953. Contribución al estudio del jurel (Trachurus trachurus L.) del Mediterráneo occidental. Publ. Inst. Biol. apl. Barcelona, Vol. 13, pp. $155-86$.

REES, G. \& Llewellyn, J., I94I. A record of the trematode and cestode parasites of fishes from the Porcupine Bank, Irish Atlantic Slope and Irish Sea. Parasitology, Vol. 33, pp. 390-6.

RusSell, F. S., I930. The seasonal abundance and distribution of the pelagic young of teleostean fishes caught in the ring-trawl in off-shore waters in the Plymouth Area. F. mar. biol. Ass. U.K., Vol. 16, pp. 707-22.

RUSSELL, F. S., I935. The seasonal abundance and distribution of the pelagic young of teleostean fishes caught in the ring-trawl in offshore waters in the Plymouth Area II. F. mar. biol. Ass. U.K., Vol. 20, pp. I47-79.

Williams, H. H., 1960. A list of parasitic worms, including 22 new records, from marine fishes caught off the British Isles. Ann. Mag. nat. Hist., Ser. I3, Vol. 2, pp. 705-15. 